\title{
RETÓRICA, SOLIDARIEDADE E DiREITOS HUMANOS ${ }^{1}$
}

\author{
Narbal de Marsillac Fontes (UFPB) ${ }^{2}$ \\ nmfmarsillac@gmail.com
}

Resumo: Em tempos plurais hodiernos, reproduz-se um contexto em que coexistem diferentes concepções de "verdade", de "justiça" e de "vida digna". Versões de mundo e cosmovisões completamente díspares são paulatinamente legitimadas no grande processo globalizante de inscrição do outro, o que demanda um tipo de racionalidade retórica e argumentativa, única capaz de adaptar-se aos diversos topoi de um mundo cada vez mais multicultural. A proposta é acompanhar esse debate e concluir que a defesa do respeito aos direitos humanos só é possível descomprometendo-se com pressupostos metafísicos excludentes, pseudolaicos, incapazes de gerar respeito mútuo e solidariedade entre todos os interlocutores.

Palavras-chave: Retórica. Argumentação. Globalização. Direitos Humanos. Solidariedade.

\section{INTRODUÇÃO}

"De longe, as pessoas são todas iguais"

(Rita Lee)

Pensar os direitos humanos num contexto em que se reconhece cada vez mais nitidamente o caráter retórico e adaptado dos discursos científicos (HABERMAS, 2002) ${ }^{3}$,

\footnotetext{
${ }^{1}$ Recebido em: 02-05-2018/ Aprovado em: 21-07-2018/ Publicado on-line em: 01-02-2019.

${ }^{2}$ Narbal de Marsillac Fontes é Professor de Filosofia da Universidade Federal da Paraíba, João Pessoa, PB, Brasil.

${ }^{3}$ Pergunta o pensador alemão na apresentação de sua obra: "por que será que os textos filosóficos, apesar de seu caráter nitidamente retórico, não se transformam em literatura?" (Nosso grifo)
} 
mesmo os que provêm de campos do saber antes tidos por apodíticos e já há muito matematizados (WANDER, 1983), parece se configurar hoje num dever fundamental de quem se debruça sobre esse tema (MARSILLAC, 2006). Como pano de fundo, temos uma crítica à própria racionalidade (MARSILLAC, 2011) e às formas tradicionais de pensar que buscam precipuamente fundamentos ou alicerces seguros e inamovíveis. A proposta aqui foi pensar esses direitos a partir do artifício retórico do conceito de solidariedade que se vê assim esvaziado de toda substância ou conteúdo permanente, mas antes, dotado de uma maleabilidade intersubjetiva que serve ou funciona na medida mesma que se mostra, para os participantes de um dado jogo de linguagem (WITTGENSTEIN, 2000, p. 30), como um conceito provisoriamente interessante. Não há assim apelo a espelhamentos ou adequações a uma realidade em si que vai paulatinamente perdendo sua importância, suspendendo toda coercitividade do mundo pela revelação crescente do caráter de indigência de toda e qualquer positividade (VATTIMO, 2002, p. 13) que, enquanto tal, afirmada e defendida por sua aparente obviedade e caráter inequívoco e aretórico, compromete-se com um determinado viés ideológico que perpetua um status quo incapaz hoje de incluir e promover a todos. Já há muito Nietzsche defendia que a falta de sentido histórico é o defeito hereditário de todos os filósofos (NIETZSCHE, 1999, p. 71). Compete, pois, às novas gerações reconhecer que também somos históricos e que mesmo a versão de mundo que nos é mais cara provavelmente será abandonada num futuro próximo. Nutrindo fundadas suspeitas acerca do caráter ideológico do ideal 
de um encontro com culturas radicalmente outras (VATTIMO, 2002, p. 158).

Assim, procuramos expor primeiramente o que ficou conhecido como panargumentativismo e relacioná-lo com o caráter necessariamente histórico e epocal de toda reflexão, inclusive a que hoje se apresenta aqui, suscitando modéstia suficiente (NIETZSCHE, 1999, p. 71) para pensarmos o segundo ponto que relaciona retórica, pluralismo e inclusão, já que incluir verdadeiramente é incluir o diferente, aquele que não tinha sido considerado no momento da elaboração do discurso, dando a este último o necessário caráter de provisoriedade próprio de quem quer levar em consideração a todos e a todas no planeta. Num terceiro momento, discutimos a chamada redignificação da retórica na filosofia contemporânea que ainda causa, no Brasil, escândalos e surpresas, mas que vem aliada aqui à solidariedade entendida, como quis Rorty, como uma expansão do que entendemos como nós (RORTY, 1992). E finalmente, terminamos relacionando direitos humanos e argumentação dando ênfase à obrigatoriedade moral de adaptação do discurso sobre esses direitos à realidade do outro, uma vez que argumentar é essencialmente adaptar-se (PERELMAN, 2002, p. 125).

\section{Panargumentativismo e História}

$\mathrm{Na}$ oposição tradicional entre Filosofia e Retórica, esta última, depois de séculos de desprezo e desqualificação, vem recuperando lentamente seu espaço original na lida com o logos e no debate enquanto lógica não-formal da praxis e da decisão racional. A controvérsia nasce, como sustenta 
Perelman, entre dois ideais de vida: um contemplativo, que busca o que é definitivamente verdadeiro e bom, e outro, ativo, mais preocupado com a consideração, permanentemente atenta, com a concretude e a eficácia argumentativa dos discursos. Com o título "Tudo é um Argumento", o livro de Lunsford da Universidade de Stanford (LUNSFORD, 2010), sinaliza um crescente movimento panargumentativista de reconhecimento do caráter circunstanciado de todo dizer; como quis a professora americana, os dias atuais impõem a todos e a todas elaborar argumentos persuasivos e éticos num mundo onde esta habilidade se torna cada vez mais essencial (LUNSFORD, 2010, p. 5). E por que é cada vez mais essencial saber argumentar no mundo contemporâneo? Na verdade, a argumentação sempre foi, ao longo da história, imperiosa. Mas, com a ascensão, em diferentes épocas, de uma cultura valorizadora dos princípios apodíticos, acreditou-se, por muito tempo, que se poderia pensar sem argumentar, como num verdadeiro cálculo matemático aonde se chega a verdades inequívocas a partir da subsunção a premissas igualmente incontestáveis. Era o projeto de uma filosofia, como quis Descartes, more geometrico (PERELMAN, 1993, p. 167)

A ambição de elaborar uma filosofia na qual todas as teses seriam quer evidentes quer demonstráveis, de uma forma constringente, tem por consequência a eliminação de toda forma de argumentação, de rejeitar a retórica como instrumento da filosofia (PERELMAN, 1993, p. 167).

A filosofia, assim, estaria, de certa forma, já pronta, como a própria ciência, cabendo aos teóricos apenas encontrá-la (PERELMAN, 1993, p. 167), desvelando 
igualmente os primeiros princípios evidentes que deveriam reger todo pensar. Nenhum papel relevante é atribuído às opiniões e a capacidade criativa de quem pensa é desprezada. Toda controvérsia é vista como um erro a ser superado por um posicionamento quiça mais crítico.

Tal (im)postura só se configura como se pudessem ser encontrados princípios ou verdades evidentes e válidas para todos os seres de razão. Ou seja, premissas incircunstanciadas. Haveria, nestes termos, uma única razão que, de certa forma, seria capaz per se de padronizar o que todos e todas no planeta pensam sobre o mundo, sobre si mesmos, sobre a vida. Pressupõe-se aqui uma mesma ipseidade para o fenômeno humano que nos força a lembrar das palavras de Rita Lee supracitadas. Foi a distância que nos possibilitou o dizer pretensamente incircunstanciado porque de longe, e tão somente de longe, somos de fato todos iguais. Parafraseando, com Santos (2000, p.15), o filósofo Epicarmo, diríamos antes que: seres históricos deveriam ter apenas pensamentos históricos, seres culturais, apenas pensamentos culturais. Ou seja, o que durante séculos foi tido por verdadeiro, correto ou belo pode ser sempre revisto em períodos subsequentes, o que atesta o seu caráter contingente e não necessário, como se pensou. Sobre isso, Grize sugere o exemplo de como Einstein destronou as certezas de Newton (GRIZE, 1982): "Desde que, segundo a fórmula de Einstein, o homem ousou reconsiderar um axioma, nós aprendemos a duvidar de que seja possivel apreender a verdade através da razão e os quarks não nos parecem mais reais que os snarks" (Referência a obra Alice no País das Maravilhas de Lewis Carrol). E assim toda história do pensamento se 
configurou numa permanente reconsideração, sempre renovada, de certezas e perspectivas passadas. Continua Grize

A história da ciência, mesmo que superficialmente examinada, permite extrair alguns aspectos importantes do esforço racional. $\mathrm{O}$ que há de mais constante pode ser, o que se vê de Aristóteles a Carnap, é o cuidado de dar às palavras uma significação unívoca e totalmente determinada. Sem cessar, o teórico retorna suas definições, as modifica, as completa. Introduz termos novos ou distinções mais sutis e assim, pouco a pouco, a margem de incerteza e ambiguidade diminuem, a parte subentendida se reduz...Assim considera-se um segundo aspecto: a hostilidade contra o que é azar, imprevisibilidade, novidade verificável. Há na razão como uma necessidade de eliminar o tempo de suas contribuições, de eliminar o sujeito sobre o qual jamais se sabe o que passará pela sua cabeça, de ter já diante de si tudo que pode ser dito de um objeto dado. Sob um outro ângulo, tudo se passa como se o esforço científico fosse a expressão de uma preguiça fundamental (GRIZE, 1982, p.37. Grifo nosso).

A necessidade de eliminar o tempo porque se tem, em última instância, preguiça de pensar, como sugere Grize, é similar à necessidade de se eliminar de toda reflexão a história, a cultura, aspectos sociais. Trata-se, pois, de eliminar todas as circunstâncias, os espaços e, com isso, inviabilizar a própria necessidade de se argumentar. Já que, de premissas absolutamente seguras, atemporais e não-situadas, demonstra-se e não se argumenta, transferindo-se para as conclusões o mesmo estatuto incircunscrito dado aos pontos de partida. Como sustenta também Perelman: toda argumentação é indicio de uma dúvida (PERELMAN, 2002, p. 544). Se não há dúvida, os interlocutores razoáveis estariam coagidos a aceitar os resultados da subsunção às tais premissas inequívocas, sob pena de serem desqualificados. 
Bem diferente disso, Lunsford ensina que pessoas andam, falam e respiram persuasão tanto quanto respiram ar: tudo é potencialmente argumento (LUNSFORD, 2010, p. 5). Argumentos estão espalhados em todos os lugares que olhamos, no que ouvimos ou lemos. São inseparáveis da própria linguagem e dos ambientes de enunciação (DUCROT, 1987), da fala entendida no seu sentido performático (MARSILLAC, 2014, p. 165-182).

\section{Retórica, PluRAlismo e INClusão}

De onde vem, pois, a hostilidade de um certo tipo de razão contra a inovação e o diferente? Por que há, em geral, uma preguiça no pensar, como sustenta Grize? Por que tendemos a rejeitar a polissemia e o pluralismo e qualificá-los como irracionais? Talvez Perelman, uma vez mais, possa nos ajudar. Como ele ensina: a maioria dos homens admite com maior boa vontade as teses que lhes agradam (PERELMAN, 2002, p. 537). É o chamado wishful thinking que nos leva a ver e aceitar, com mais facilidade, o que nos é familiar, o que consideramos ordinário ou comum. Na linguagem do poeta, seria defender que narciso acha feio o que não é espelho ${ }^{4}$.

Qualquer acordo espontâneo entre indivíduos e grupos sobre o que fazer cria uma forma de comunidade e, com sorte, será o estágio inicial na expansão dos círculos daqueles a quem cada parte do acordo previamente tomou como "pessoas como nós". Dessa forma, a oposição entre argumentação racional e sentimentos de companheirismo começa a se dissolver (PERELMAN, 2002, p. 512).

Bauman, falando desses processos de globalização,

\footnotetext{
${ }^{4}$ Música Sampa de Caetano Veloso
} 
fenômeno que considerava destinal e inevitável (BAUMAN, 1998, p.7), deu o nome sugestivo de batalha dos mapas à imposição colonialista de uma única legibilidade do espaço que visava, em última instância, neutralizar o impacto da variedade e da contingência (BAUMAN, 1998, p.35). Seria o correlato espacial de uma racionalidade demonstrativa que recusa e desqualifica o diferente, vendo o pluralismo como uma ameaça, um flanco aberto na armadura do pensar correto e verdadeiro. Bem diferente disso, é tão somente o pluralismo que pode apurar nosso sentido crítico e as controvérsias normalmente não conduzem a unanimidade (PERELMAN, 1993, p. 170). O que nos leva a pensar o próprio pensar, descolonizado e livre, como necessariamente argumentativo, isto é: sempre situado e circunscrito.

Em vez de procurar uma verdade primeira, necessária e evidente, da qual dependeria todo o nosso saber, organizemos a nossa filosofia em função de uma visão na qual são os homens e as sociedades em interação os únicos responsáveis pela sua cultura, pelas suas instituições e pelo seu futuro, os quais se esforçam por organizar sistemas razoáveis, imperfeitos, mas aperfeiçoáveis (PERELMAN, 1993, p. 171).

Ou seja, uma racionalidade apodítica que se crê a si mesma capaz de encontrar princípios primeiros absolutamente incontroversos a partir dos quais subsumir-seia todo pensar, apesar de forjada num contexto epocal específico, pretendeu pular para fora da história e, de muito longe, viu como único o que, de perto, é plural. Tal pretensa univocidade se configura como uma ideologia perversa da produção da ausência e exclusão do outro. A plurivocidade do mundo, no entanto, fez-se ouvir no processo permanentemente crescente de inscrição do outro a que se 
deu o nome de globalização que revela que a compreensão de mundo excede em muito a compreensão ocidental de mundo (SANTOS, 2013, p. 26). Atualmente, testemunhamos, com a globalização, o fracasso generalizado de concepções de mundo monolíticas e o esfacelamento das pretensões teóricas monoculturais que cedem paulatinamente seu espaço de legitimidade para outras formas múltiplas de afirmação de si de cunho eminentemente étnico, religioso, nacionalista (RORTY, 2001, p. 480). Culturas marginais e minorias recebiam antes menos atenção e cuidado porque eram excessivamente distintas do resto do globo, mas desde que nós, ocidentais, inventamos a antropologia cultural, nos tornamos conscientes da humilhação causada pela arrogância colonial (RORTY, 1992, p. 119). Entretanto, ainda hoje, porque não nos espelha, uma quantidade infinda de seres humanos é desprezada, excluída e barbaramente mantida afastada do mínimo existencial. Talvez ajudaria imaginar quais seriam as reações dos países europeus que recebem de mau grado imigrantes se estes fossem todos e todas loiros e de olhos azuis[...] Parafraseando Rorty: As paisagens democráticas $e$ de respeito aos direitos humanos parecem sempre terminar em arame farpado (RORTY, 1992, p. 119).

\section{REDIGNIFICAÇÃO DA RETÓRICA E A SOLIDARIEDADE}

A redignificação contemporânea da retórica está, assim, relacionada a uma maximização do papel da linguagem para o pensar, a uma tomada de consciência crescente do caráter artificial de todas as gramáticas e de todos os conceitos e, portanto, de suas respectivas circunscrições. Fazendo da 
solidariedade, entendida como uma ampliação do nós, uma identidade imaginativa mais ampla, não como quiseram os cristãos para quem "todos são filhos de Deus”, ou Kant para quem "são dignos todos os seres racionais", mas antes como recurso hábil e poderoso, reconhecidamente retórico (RORTY, 1992, p. 239), fruto do amadurecimento dos vocabulários morais e políticos que independem de pressupostos religiosos ou filosóficos, como o quis Rorty:

Trata-se de contingências que deram origem ao desenvolvimento de vocabulários morais e políticos típicos das sociedades democráticas secularizadas do Ocidente. À medida que esse vocabulário foi gradualmente tornado não teológico e não filosófico, a "solidariedade humana" emergiu como recurso retórico poderoso (RORTY, 1992, p. 239. Grifo nosso).

Parece-nos hoje mais interessante, em termos políticos e morais, concentrar nossas energias no intuito de eliminar todas as formas de humilhação e crueldade, ampliar o "nós" e o sentimento de co-pertencimento, ao ponto extremo de incluir não só todos os humanos, mas também nãohumanos, florestas, mares e o próprio planeta ${ }^{5}$. Não porque se tenha razões ou fundamentos necessários para tal empreitada, mas simplesmente porque nos parece mais proveitoso e interessante alargar tanto quanto possamos o nosso sentido de nós (RORTY, 1992, p. 243)

O progresso moral existe, e esse progresso vai efetivamente na direção de uma maior solidariedade humana. Mas tal solidariedade não é pensada como sendo o reconhecimento de um eu central, da essência humana em todos os seres humanos. É antes pensada como sendo a

\footnotetext{
${ }^{5} \mathrm{O}$ exemplo mais interessante e recente está expresso no artigo 71 da Constituição do Equador, in verbis: "A Natureza ou PachaMama (Terra Mãe) tem o direito (humano) a que se respeite integralmente sua existência"
} 
capacidade de ver cada vez mais diferenças tradicionais (de tribo, religião, raça, costumes, etc) como não importantes, em comparação com semelhanças no que respeita à dor e à humilhação - a capacidade de pensar em pessoas muito diferentes de nós como estando incluídas na esfera do "nós" [...] (Assim) os principais contributos do intelectual moderno para o progresso moral são descrições pormenorizadas de variedades particulares de dor e humilhação e não tratados filosóficos ou religiosos (RORTY, 1992, p. 239).

Assim, em seu antifundacionalismo, Rorty defende que Literatura, cinema, teatro e as artes em geral podem, mais do que tratados sobre ética, identificar moralidade com os sentimentos que são suscitados diante da dor e da humilhação do outro, expandindo o sentido de solidariedade pela expansão mais inclusiva do que entendemos como "nós" e pela sublimação do desejo de evitar toda forma de crueldade e sofrimento. O que faz da própria reflexão filosófica um esforço em nos tornar mais sensíveis à toda forma de vida que nos rodeia (RORTY, 2005, p. 13), a nos aproximarmos mais do mundo, fazendo o caminho inverso daquele sugerido por Platão e sua metafísica. $\mathrm{O}$ progresso ético mais do que aumentar o respeito a princípios e regras morais pré-existentes, ahistóricas e descontextualizadas, traduz-se num verdadeiro aumento cada vez mais amplo da empatia, da compaixão e do cuidado com os outros seres e de suas necessidades, respondendo, gradualmente melhor, os anseios de grupos cada vez mais inclusivos. Aqui, conhecimento não é um bem em si, mas um meio contingente e histórico de eliminar toda forma de humilhação e sofrimento e alcançar um espectro paulatinamente mais amplo da realização e felicidade humana (RORTY, 2005, p. 81). 
Muito depois de nossa morte, pessoas melhores e mais sofisticadas talvez considerem nossas ações um erro trágico, assim como talvez julguem nossas crenças científicas apenas inteligíveis segundo um paradigma já então obsoleto (RORTY, 1999, p. 82).

Em outras palavras, não há o último historiador e pensar sê-lo é acreditar ter uma Visio Dei inatingível para mortais como nós; agindo-se, assim, diabolicamente, como o quis Gadamer, por pretender ser como o próprio Deus (GADAMER, 1997, p. 578), intentando fazer inconscientemente que o mundo inteiro esteja assujeitado à sua verdade ou à sua percepção de bem ou de vida digna. Muito pelo contrário, como já se disse aqui, seres históricos devem ter pensamentos históricos, e o que hoje chamamos filosófico e científico podem ser, num futuro próximo, chamados de mito (KHUN, 2011, p. 21) ${ }^{6}$. Não há garantias, muito menos certezas definitivas. Atento a isso, Feyerabend sustenta que nenhum princípio resiste à pesquisa histórica (FEYERABEND, 2007, p. 37), impossibilitando toda sorte de uso exclusivamente apodítico da razão. Mesmo searas antes blindadas contra a argumentação e contra toda espécie de retoricidade, como a lógica e a matemática em geral, hoje revelam seu caráter circunscrito a campos-argumentativos específicos (REYES, 2004) ${ }^{7}$, como sustenta Gadamer: Não pode haver nenhum esforço histórico e finito do homem que possa apagar os indícios dessa finitude. Também as ciências da

\footnotetext{
${ }^{6}$ In verbis: "Se essas crenças obsoletas devem ser chamadas de mitos, então os mitos podem ser produzidos pelos mesmos tipos de métodos e mantidos pelas mesmas razões que hoje conduzem ao conhecimento científico".

${ }^{7} \mathrm{O}$ debate sobre a presença da retórica também na Matemática já está consagrado no conceito de Mathematical Rhetoric em autores como Wander, P. The Rhetoric of Science. In: Western Journal of Speech communication, 1976, ou Why all Knowledge is Rhetorical, in: Journal of the American Forensic Association, 1983. Também GROSS, A. G. The Rhetoric of Science. Cambridge; Harvard University Press, 1990 e CAMPBELL, J. A. The Rhetorical Turn in Science Studies, in: Quartely Journal of Speech, 1996.
} 
matemática e da natureza são uma porção dessa história humana (GADAMER, 1997, 375).

\section{Direitos Humanos E ARgumentaÇão}

Dessa mesma forma e seguindo a mesma perspectiva tradicional desprestigiadora da retórica e da argumentação em geral, as diversas teorias universalistas dos direitos humanos também foram pensadas a partir daquilo que Toulmin chamou de paradigma analítico (TOULMIN, 2006, p. 222) que vê a lógica como modelo de racionalidade e que gera o que chamou de esquizofrenia da filosofia ou de delírio filosófico que o leva a sustentar que não há nenhuma justificativa para aplicar indiscriminadamente critérios analíticos em todos os campos de argumentos (TOULMIN, 2006, p. 252). Nesse sentido, a aparente vitória de uma concepção planetária de direitos humanos apenas denuncia o fracasso e desrespeito a esses mesmos direitos humanos que, indiferente às diferenças, vê, de longe, como iguais uma miríade de gramáticas distintas da dignidade humana e da vida digna (SANTOS, 2013, p. 15). Vendo-as como idênticas e insensíveis ao que lhes faz singular, nos familiarizamos mais facilmente com toda sorte de desrespeito, violação e humilhação que não são consideradas por nós como violação daqueles direitos humanos (SANTOS, 2013, p. 16), pois à aparente universalidade e legitimidade desses direitos se aliam jogos de poder capitalistas, colonialistas e sexistas que subalternizam e desqualificam subterraneamente uma gama gigantesca de grupos humanos e de culturas inteiras, com seus saberes próprios, seus valores, seus princípios, suas 
crenças. Para confirmá-lo, basta ver os critérios de avaliação do respeito a esses direitos e como estão relacionados aos polos de invisibilidade e de supervisibilidade intimamente correlacionados com os imperativos da politica externa norteamericana (SANTOS, 2010, p. 444).

Bem diferente disso, uma compreensão retóricoargumentativa dos direitos humanos se preocupa primeiramente com as características particulares daqueles a quem são endereçados esses discursos porque toda argumentação se desenvolve consoante o auditório ao qual se dirige e ao qual o orador é obrigado a adaptar-se (PERELMAN, 1997, p. 304). Assim, mais do que buscar fundamentos descontextualizados, gerais e abstratos, os que argumentam precisam ter em conta que a força persuasiva de seus discursos vem justamente do momento concreto em que são proferidos (PERELMAN, 1997, p. 385) ${ }^{8}$, da adaptação e valorização do que é singular e único, dos fatores históricos, culturais e sociais daqueles que nos ouvem, forçando-nos a diferenciar o que é efetivamente diferente, o que prioriza saberes e cosmovisões locais em detrimento dos princípios pretensamente intemporais do que podemos chamar de senso comum dos direitos humanos convencionais (SANTOS, 2013, p. 18).

\section{CONCLUSÃO}

Pensar a obrigação moral, em qualquer uma de suas formas, como fruto de uma racionalidade fundada em princípios primeiros não-situacionais e aretóricos, em certa medida,

\footnotetext{
${ }^{8}$ In verbis: "não há argumento que não receba sua força do momento em que é empregado".
} 
desumanizou as considerações éticas em geral, esterilizandoas, porque partiu-se do pressuposto, como se procurou mostrar aqui, de que seres humanos são todos iguais e igualmente assujeitados e assujeitáveis a um mesmo corpo de premissas. Tal discurso só foi possibilizado pelo distanciamento metafísico ínsito em tais considerações. Se a proposta sugerida consiste antes numa permanente aproximação do mundo da vida, é a contingência, a pluralidade e as diferenças que passam a reinar soberanas nesse novo império retórico 9 que renasce das cinzas, como uma verdadeira Fênix, para nos ensinar a abandonar a preguiça fundamental do pensar que se pretendeu atópico e incircunscrito, ahistórico e transcultural e a abraçar o desafio de manter a porta sempre entreaberta pela constante possibilidade de consideração das perspectivas até então impensadas do outro. É reconhecer a necessidade também permanente de se ser mais modesto diante das múltiplas possibilidades dos fluxos da vida, dos acontecimentos, das interpretações que estão por vir. É reconhecer que, conosco e com nossas mais altas considerações, a história não se finda.

Abstract: In plural nowadays, we reproduce a context in which coexist different conceptions of "truth", of "justice" and of "decent life". Versions of the world and different cosmovisions have been slowly legitimated in the great global process of the other's inscription, which requires one type of rhetorical and argumentative rationality, the only one capable to adapt to the different topoi of a more and more multicultural world. We intent to follow this debate and conclude that the defense of human rights is only possible if we decompromise ourselves with the metaphysical assumptions, excluding, so-called laic, uncapable to generate mutual respect and solidarity between the speakers.

Keywords: Rhetoric. Argumentation. Globalization. Human Rights. Solidarity.

\footnotetext{
${ }^{9}$ Referência à obra de Perelman com o mesmo nome
} 


\section{REFERÊNCIAS}

BAUMAN, Zigmunt. Globalização: As Consequências Humanas. Trad. Marcus Penchel. Rio de Janeiro: Zahar, 1998. DUCROT, Oswald. O Dizer e o Dito. Trad. Eduardo Guimarães. Campinas; São Paulo, 1987.

FEYERABEND, Paul. Contra o Método. Trad. Cezar Augusto Mortari. São Paulo: Edidora da Unesp, 2007.

GADAMER, H. Verdade e Método I. Trad. Flávio Paulo Meurer. Petrópolis: Vozes, 1997.

GRIZE, Blaize. De la Logique à l'Argumentation. Genève: Librairie Droz, 1982.

HABERMAS, J. Pensamento Pós-Metafísico. 2. ed. Trad. Flávio Breno Siebeneichler. Rio de Janeiro: Tempo Brasileiro, 2002.

KHUN, Thomas. A Estrutura das Revoluções Científicas. Trad. Beatriz Vianna Boeira. 10. ed. São Paulo: Perspectiva, 2011.

LUNSFORD, Andrea et alii. Everything's an argument. 5. ed. Boston: Dornnelly and Sons Company, 2010.

MARSILLAC, Narbal. Viragem Retórica, Viragem Pragmática e Superação da Metafísica. Revista Aufklarung, p. 165-182, out. 2014.

- Racionalidade Retórica e Argumentativa. Revista Princípios, v. 18, n. 30, jul/dez. 2011.

. Direitos Humanos e Comunidade Internacional de Espíritos. Revista Ethica, v. 14, n. 1, 2007. 